\title{
SYNTHESIS AND ANTIOXIDANT CAPACITY OF (CHLOROBENZYLIDENE)HYDRAZINYL-THIAZOLES
}

\author{
ADRIANA GROZAV ${ }^{a}$, DANIELA HANGANU ${ }^{a}$, OVIDIU CRISAN ${ }^{a}$, \\ DAN PORUMB ${ }^{b}$ AND CASTELIA CRISTEA ${ }^{b}$
}

\begin{abstract}
. 2-(chlorobenzilidene)hydrazinyl-thiazole derivatives were conveniently prepared by Hantzsch reaction protocol, starting with thiosemicarbazone and ethyl 2-bromo-3-oxo-3-phenylpropanoate. Their antioxidant capacity was screened by electron transfer based assays. The results of both DPPH (1,1-Diphenyl-2-picrylhydrazyl) free radical scavenging, as well as Ferric lon Reducing Antioxidant Power (FRAP) assay, indicated antioxidant capacity for the tested hydrazone derivatives. At the concentration of $9.5 \mu \mathrm{g} / \mathrm{mL}$, the DPPH radical scavenging activity of ethyl 2-(2-(3chlorobenzylidene)hydrazinyl)-4-phenylthiazole-5-carboxylate was found to be more than $93 \%$.
\end{abstract}

Keywords: synthesis, thiazoles, antioxidant capacity, DPPH, FRAP

\section{INTRODUCTION}

The literature data designate the thiazole derivatives as an important class of heterocyclic compounds exhibiting remarkable pharmacological activities. The thiazole core can be often recognized in the structure of commonly used antimicrobial, antifungal or antiretroviral agents, as well as nonsteroidal anti-inflammatory drugs. [1.].

\footnotetext{
a Faculty of Pharmacy, "Iuliu Hațieganu" University of Medicine and Pharmacy, RO-400012, Victor Babes 41, Cluj-Napoca, Romania

b "Babeș-Bolyai" University, Faculty of Chemistry and Chemical Engineering, RO-400028, Cluj-Napoca, Romania

*Corresponding author: dhanganu@umfcluj.ro
} 
Our previous results in the synthesis and characterization of biologically active novel thiazole derivatives described several 2-hydrazinyl-thiazole derivatives which displayed antibacterial, analgesic, or anti-inflammatory activities [2-5]. Various heterocyclic systems containing thiazole units joint or fused to other aromatic moieties were synthesized and several aspects of their biological activities were described; thus, some benzothiazolophenothiazine derivatives exhibited antimicrobial activity [6-9], while bis(thiazolyl)-, phenothiazinyl- and indolyl-thiazolylhydrazine derivatives were screened for their anticancer potential [10-19] in search for new antitumour agents producing less hypersensitivity side reactions (which might occur due to platinum complexes which are currently employed in the cancer therapy. [20]). Two ((1H-indol-5yl)methylene)-hydrazinyl)-thiazole derivatives were found to be promising antioxidant agents based on DPPH (1,1-Diphenyl-2picrylhydrazyl) radical scavenging assay; the chemoselectivity of radicals formation was supported by theoretical computational data indicating the extraction of the hydrogen atom from the $\mathrm{NH}$ group located in the hydrazinyl bridge rather than in the indole heterocyclic unit. [19]

In this work, we present an extension of our investigations in the area of thiazole derivatives by describing the synthesis and antioxidant capacity of two additional 2-((chlorobenzylidene)hydrazinyl)-thiazole derivatives. A comparison of the antioxidant capacity of thiazole derivatives with their thiosemicarbazone synthetic precursors and typical control compounds (Trolox and Ascorbic acid) was enabled by the results displayed in DPPH radical scavenging activity and ferric reducing antioxidant power (FRAP) assays.

\section{RESULTS AND DISCUSSION}

\section{Synthesis of 2-(chlorobenzylidene)hydrazinyl)-thiazole derivatives}

The synthetic route towards the 2-(chlorobenzylidene)hydrazinylthiazoles $\mathbf{3 a , b}$ was designed by taking advantage from the broad scope of the Hantzsch reaction [21]. Thus, thiosemicarbazone precursor $\mathbf{2 a} \mathbf{a} \mathbf{b}$ (previously prepared by the condensation of chloro-benzaldehyde derivatives 1a,b [2]) and ethyl 2-bromo-3-oxo-3-phenylpropanoate were subjected to the cyclocondensation reaction as shown in Scheme 1. 
<smiles>[X]c1ccc(C=O)c([X])c1[X]</smiles>

1a: $X=X^{\prime \prime}=\mathrm{H}, X^{\prime}=\mathrm{Cl}$ 1b: $X=X^{\prime \prime}=\mathrm{Cl}, X^{\prime}=\mathrm{H}$

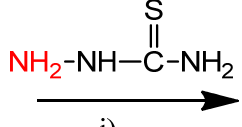

i)<smiles>[X]c1ccc(C=NNC(N)=S)c([X])c1[X]</smiles>

2a: $X=X "=H, X '=C l$

2b: $X=X "=C l, X^{\prime}=H$

$2 \mathrm{a}, \mathrm{b}+$<smiles>CCOC(=O)C(Br)C(=O)c1ccccc1</smiles><smiles>C=CC</smiles><smiles>[X]c1ccc(C=NNc2nc(CCCC)c(C(=O)OCC)s2)c([X])c1[X]</smiles>

3a: $X=X^{\prime \prime}=\mathrm{H}, X^{\prime}=\mathrm{Cl}$

3b: $X=X^{\prime \prime}=\mathrm{Cl}, X^{\prime}=\mathrm{H}$

Scheme 1. Synthesis of 2-(chlorobenzylidene)hydrazinyl-thiazole derivatives; conditions: i) ethanol, $2 h$, reflux, ii) Acetone/DMF (v/v): 1/0.2, 24h, r.t.

The structures of thiosemicarbazone intermediates $\mathbf{2 a , b}$ and 2(chlorobenzylidene)-hydrazinylthiazole derivatives $\mathbf{3 a , b}$ were confirmed by NMR spectroscopic data.

\section{Antioxidant capacity}

The antioxidant ability of chemical compounds might be due to free radicals scavenging, metal ions chelating and hydrogen atoms or electrons transferring [22]. In our study, the antioxidant capacity of the synthesized series of hydrazone derivatives was screened by using electron transfer based assays measuring the capacity of an antioxidant in the reduction of an oxidant which changes colour upon reduction. The UV-Vis spectrophotometric monitoring of the reaction offered the possibility of correlating the degree of colour change with the antioxidant concentration. As it may be seen from table 1, thiosemicarbazones $2 \mathbf{2 a , b}$ and 2(chlorobenzylidene)hydrazinyl-thiazole derivatives $\mathbf{3 a}, \mathbf{b}$ displayed antioxidant capacity determined by DPPH radical scavenging and FRAP assays. 
Table 1. The antioxidant capacity of synthesized hydrazone derivatives

\begin{tabular}{|c|c|c|c|}
\hline \multirow{2}{*}{ Compound } & \multicolumn{3}{|c|}{ Methods } \\
\cline { 2 - 4 } & \multicolumn{2}{|c|}{ DPPH $50[\mu \mathrm{g} / \mathrm{mL}]$} & FRAP \\
& I $~$ & IM ET/g] \\
\hline 2a & $13.64 \pm 0.52$ & $65.50 \pm 0.64$ & $229.04 \pm 1.2$ \\
2b & $15.57 \pm 0.72$ & $56.52 \pm 0.53$ & $312.86 \pm 0.9$ \\
3a & $9.55 \pm 0.61$ & $93.88 \pm 0.72$ & $1710.38 \pm 1.5$ \\
3b & $16.45 \pm 0.37$ & $60.70 \pm 0.67$ & $11.62 \pm 0.6$ \\
\hline
\end{tabular}

In the reaction with DPPH radical, both semicarbazone derivatives $\mathbf{2 a , b}$ and 2-(chlorobenzylidene)hydrazinyl-thiazoles $\mathbf{3} \mathbf{a}, \mathbf{b}$ determined the colour change of DPPH radical solution from purple to yellow. The reaction was monitored by the decrease of absorbance intensity at $\lambda_{\max }=517 \mathrm{~nm}$, measured after a reaction time of 30 minutes. The DPPH free radicals scavenging potential of the tested compounds was expressed by:

a) the concentration of tested hydrazone derivative that causes a decrease in the initial DPPH concentration by $50 \%\left(\mathrm{IC}_{50}\right)$

b) the percent DPPH scavenging ability (I\%) was calculated as:

$$
1 \%=\left(A_{\text {control }}-A_{\text {sample }} / A_{\text {control }}\right) \times 100
$$

where $A_{\text {control }}$ is the absorbance of DPPH radical in methanol solution

$A_{\text {sample }}$ is the absorbance of DPPH radical in solution in the presence of the tested hydrazone derivative.

According to the results presented in Table 1, the DPPH free radicals scavenging potential of the tested hydrazones decreased in the following order: $\mathbf{3} \mathbf{a}>\mathbf{2} \mathbf{a}>\mathbf{2} \mathbf{b} \approx \mathbf{3} \mathbf{b}$. At the concentration of $9.5 \mu \mathrm{g} / \mathrm{mL}$, the DPPH radical scavenging activity of hydrazinyl-thiazole $3 a$ was found to be more than $93 \%$. In terms of concentration that causes a decrease in the initial DPPH concentration by $50 \%$, the antioxidant capacity of $3 a$ appears comparable to the phenolic standard Trolox $\left(\mathrm{IC}_{50}=9.74 \mu \mathrm{g} / \mathrm{mL}\right)$, but lower than the ascorbic acid standard $\left(\mathrm{IC}_{50}=2.46 \mu \mathrm{g} / \mathrm{mL}\right)$.

The reducing capacity of hydrazones $\mathbf{2 a}, \mathbf{2} \mathbf{b}, \mathbf{3 a}$ and $\mathbf{3 b}$ has been assed using the FRAP assay, which is based on another electron transfer reaction where a ferric salt, is used as an oxidant $\left(\mathrm{Fe}(\mathrm{III})(\mathrm{TPTZ})_{2} \mathrm{Cl}_{3}\right.$ where TPTZ 2,4,6-tripyridyls-triazine). The reduction of $\mathrm{Fe}^{3+}$ to $\mathrm{Fe}^{2+}$ and thus the formation of the blue coloured Fe(TPTZ) ${ }^{2+}$ complex depends on the electron donating capacity of the tested compounds, which was quantified by the UV-Vis spectrophotometric method. The reducing ability of the hydrazones decreases in the following order: $\mathbf{3} \mathbf{a}>\mathbf{2} \mathbf{b}>\mathbf{2} \mathbf{a}>\mathbf{3} \mathbf{b}$ (see Table 1 where the results are quantified as $\mu \mathrm{M}$ Trolox equivalents $/ g)$. 
The results of both electron transfer assay (the DPPH and FRAP), indicate $3 \mathbf{a}$ as the most efficient antioxidant in the tested series. A structureactivity correlation points towards a superior electron donor ability of $\mathbf{3 a}$, explainable by the presence of the pi-electron-excessive heterocycle thiazole.

The electron withdrawing effect induced by the second chlorine atom introduced as a substituent of the benzylidene aromatic ring, decreased the overall electron donor ability of $\mathbf{2} \mathbf{b}$ and $\mathbf{3 b}$ and thus their overall antioxidant capacity.

\section{CONCLUSIONS}

The results of two electron transfer assays (the DPPH assay and FRAP assay) applied in this study, indicate monochlorobenzylidenehydrazinylthiazole $\mathbf{3 a}$ as the most efficient antioxidant in the tested series containing the chlorobenzylidene-hydrazinyl-thiazole and the similarly mono and dicloro substituted thiosemicarbazones.

\section{EXPERIMENTAL SECTION}

\section{Materials and Methods}

The starting materials and solvents were obtained from commercial sources from Sigma-Aldrich. Melting points were measured with an Electrothermal IA 9200 apparatus (Bibby Scientific Limited (Group HQ), Stone, UK).

NMR spectra were recorded at room temperature on $400 \mathrm{MHz}$ Bruker Avance instruments. Chemical shifts are expressed in $\delta(\mathrm{ppm})$ relative to standard tetramethylsilane (TMS).

Compounds $\mathbf{2 a , b}$ were prepared according to the previously reported procedure [2].

General procedure for the synthesis of 2-(chlorobenzylidene)hydrazinylthiazole derivative $3 a, b$

A mixture of arylidene-hydrazine-carbothioamide $2 \mathbf{2} / \mathbf{b}(10 \mathrm{mmol})$ and ethyl-2-bromo-3-oxo-3-phenylpropanoate $(10 \mathrm{mmol})$ in acetone/DMF $(15 \mathrm{~mL}$, $V / V$ : 1/0.2) was stirred at room temperature for 20-24h. The reaction mixture was neutralized at $\mathrm{pH} 7$ with $\mathrm{NaHCO}_{3}$ aqueous solution (10\%). The precipitate was filtered and recrystallized from ethanol. 
Ethyl 2-(2-(3-chlorobenzylidene)hydrazinyl)-4-phenylthiazole-5carboxylate 3 a

White crystals, yield $82 \%$, m.p. $193-194{ }^{\circ} \mathrm{C}$,

${ }^{1} \mathrm{H}-\mathrm{NMR}\left(400 \mathrm{MHz}, \mathrm{CDCl}_{3}\right) \delta \mathrm{ppm}: 1.33\left(t, 3 \mathrm{H}, \mathrm{CH}_{3}\right), 4.3(q, 2 \mathrm{H}, \mathrm{O}-$ $\left.\mathrm{CH}_{2}\right), 6.59(s, 1 \mathrm{H}, \mathrm{CH}=\mathrm{N}), 7.18(d, 1 \mathrm{H}) 7.3(m, 3 \mathrm{H}), 7.41(t, 1 \mathrm{H}), 7.48(t$, $2 \mathrm{H}), 7.85(\mathrm{~m}, 2 \mathrm{H}), 10.5$ (broad, $1 \mathrm{H}, \mathrm{NH}$ )

Ethyl 2-(2-(2,4-dichlorobenzylidene)hydrazinyl)-4-phenylthiazole-5carboxylate $\mathbf{3 b}$

Light yellow crystals, yield $91 \%$, m.p. $208-209^{\circ} \mathrm{C}$,

${ }^{1} \mathrm{H}-\mathrm{NMR}\left(400 \mathrm{MHz}, \mathrm{CDCl}_{3}\right) \delta \mathrm{ppm}: 1.32\left(t, 3 \mathrm{H}, \mathrm{CH}_{3}\right), 4.28(q, 2 \mathrm{H}, \mathrm{O}-$ $\left.\mathrm{CH}_{2}\right), 7.22(s, 1 \mathrm{H}, \mathrm{CH}=\mathrm{N}), 7.3(m, 5 \mathrm{H}), 7.8(m, 3 \mathrm{H}), 9.9($ broad, $1 \mathrm{H}, \mathrm{NH})$

\section{Antioxidant capacity}

\section{a) DPPH Free Radical Scavenging Activity}

A DPPH solution $(0.1 \mathrm{~g} / \mathrm{L})$ in methanol was prepared and $2.0 \mathrm{~mL}$ of this solution was added to $2.0 \mathrm{ml}$ of tested compound solution (or standard) in methanol at different concentrations $(3.125-25.0 \mu \mathrm{g} / \mathrm{mL}$ for $\mathbf{2 a}, \mathbf{2} \mathbf{b}, \mathbf{3 a}$ and $9.375-37.5 \mu \mathrm{g} / \mathrm{mL}$ for $3 \mathbf{b})$. After 30 minutes of incubation at $40^{\circ} \mathrm{C}$ in a thermostatic bath, the decrease in the absorbance $(n=3)$ was measured at $517 \mathrm{~nm}$. The percent DPPH scavenging ability $(1 \%)$ was calculated as: $1 \%=$ $\left(A_{\text {control }}-A_{\text {sample }} / A_{\text {control }}\right) \times 100$, where $A_{\text {control }}$ is the absorbance of DPPH radical + methanol (containing all reagents except the sample) and $A_{\text {sample is }}$ the absorbance of DPPH radical + sample/standard. The antiradical activity (three replicates per treatment) was expressed as $\mathrm{IC}_{50}(\mu \mathrm{g} / \mathrm{mL})$, the concentration of compound required to cause a 50\% DPPH inhibition. The scavenging activity of Trolox and ascorbic acid were measured and compared with the one of the tested compounds.

\section{b) Reducing Power by Ferric Reducing Antioxidant Power (FRAP) Test}

The solutions of the tested compounds $\mathbf{2} \mathbf{a}, \mathbf{b}$ and $\mathbf{3} \mathbf{a}, \mathbf{b}$ have been prepared in $50 \mu \mathrm{g} / \mathrm{mL}$ concentration

The FRAP reagent consists in a mixture of $2.5 \mathrm{ml} 10 \mathrm{mM}$ TPTZ solution in $40 \mathrm{mM}$ hydrochloric acid to which $2.5 \mathrm{ml} 20 \mathrm{mM}$ ferric chloride solution and $25 \mathrm{ml}$ acetate buffer at $\mathrm{pH}=3.6$ is added. At $0.4 \mathrm{~mL}$ of diluted sample $(50 \mu \mathrm{g} / \mathrm{mL}), 6 \mathrm{~mL}$ the FRAP reagent was added and absorbance was measured at $595 \mathrm{~nm}$ after $10 \mathrm{~min}$. Blank consisted in the similar mixture without the sample. Results are expressed as $\mathrm{mM}$ Trolox equivalents/g compound, using a calibration curve $\left(R^{2}=0.989\right)$ constructed with $10-40 \mathrm{mg} / \mathrm{L}$ Trolox standard. 


\section{ACKNOWLEDGMENTS}

Financial support from the Romanian Ministry of Education and Research (PN-II-ID-PCE-2012-4-0488) is greatly acknowledged. This work was supported also by the Swiss Enlargement Contribution in the framework of the Romanian-Swiss Research Program, project number IZERZO-142198/1. This paper was published under the frame of European Social Found, Human Resources Development Operational Programme 2007-2013, project no. POSDRU/159/1.5/S/136893".

\section{REFERENCES}

1. R. Mishra, P. K. Sharma, P. K. Verma, I. Tomer, G. Mathur, P. K. Dhakad, J. Heterocycl. Chem., 2017, 54(4), 2103.

2. A. Grozav, L. I. Găină, V. Pileczki, O. Crisan, L. Silaghi-Dumitrescu, B. Therrien, V. Zaharia, I. Berindan-Neagoe, Int. J. Mol. Sci., 2014,15(12), 22059.

3. A. Grozav, B. Stancu, C. Boari, F. Chirila, N. Fit, C. Cristea, Studia UBB Chemia, 2017, 62(2), 365.

4. A.C. Cosma, A. Ignat, I.C. Tarca, V. Zaharia, S. D. Bolboaca, L. Jantschi, Rev.Chim., 2018, 69 (4), 777.

5. B. Brem, E.Gal, L. Găină, L.Silaghi-Dumitrescu, E. Fischer-Fodor, C. I. Tomuleasa, A. Grozav, V. Zaharia, L. Filip, C. Cristea, Int. J. Mol. Sci., 2017, 18(7), 1365.

6. A.T. Mbaveng, A. Grozav Ignat, B. Ngameni, V. Zaharia, B.T. Ngadjui, V. Kuete; BMC Pharmcol. Toxicol., 2016, 17 (3).

7. M. Sabou, A. Grozav, L. M. Junie, M. Flota, V. Zaharia, C. Cristea, Studia UBB Chemia, 2016, 61(3), 117.

8. A. Grozav, V. Zaharia, C. Cristea, N. I. Fit, Studia UBB Chemia, 2015, 60(3), 283.

9. B. Bream, E. Gal, C. Cristea, L. Gaina, A. Grozav, V. Zaharia, L. SilaghiDumitrescu, Studia UBB Chemia, 2015, 60(2), 371.

10. M. A. Pop, T. C. Drugan, A. Grozav, B. Domokos, A. Urda, C. M. Pop, Studia UBB Chemia, 2014, 59(3), 119.

11. A. Ignat (Grozav), L. Gaina, V. Kuete, L. Silaghi-Dumitrescu, T. Efferth, V. Zaharia, Molecules, 2013, 18(4), 4679.

12. V. Zaharia, A. Ignat (Grozav), B. Ngameni, V. Kuete, M. L. Moungang, C. N. Fokunang, M. Vasilescu, N. Palibroda, C. Cristea, L. Silaghi-Dumitrescu, B. T. Ngadju, Med. Chem. Res., 2013, 22, 5670.

13. A. Ignat (Grozav), T. Lovasz, M. Vasilescu, E. F. Fodor, C. B. Tatomir, C. Cristea, L. Silaghi-Dumitrescu, V. Zaharia, Archiv Der Pharmazie, 2012 , 345 (7), 574.

14. A. Cozma, L. Vlase, A. Ignat (Grozav), V. Zaharia, S. Gocan, C. Marutoiu, A. Fodor, Rev. Chim., 2012, 63(7), 651.

15. A. Cozma, L. Vlase, A. Ignat, (Grozav), V. Zaharia, S. Gocan, N. Grinberg, J. L. Chromatogr. Relat. Technol., 2012, 35(1-4), 590.

16. V. Zaharia, A. Ignat (Grozav), N. Palibrod, B. Ngameni, V.Kuete, C. N. Fokunang, M. L. Moungang, B. T. Ngadjui, Eur. J. Med. Chem., 2010, 45(11), 5080. 
17. A. Ignat (Grozav), V. Zaharia, C. Mogoşan, N. Palibroda, C. Cristea, L. SilaghiDumitrescu, Farmacia, 2010, 58 (3), 290.

18. M. Abdel-Maksouda, U.M. Usama, O. Chang-Hyun, Bioorg. Med. Chem., 2019, 27(10), 20141.

19. A. Grozav, I. D. Porumb, L. I. Găină, L. Filip, D. Hanganu, Molecules, 2017, 22(2), 260.

20. S. Cetean, T. Ciuleanu, D. C. Leucuta, C. Cainap, A. M. Constanti, I. Cazacu, S. Cainap, A. Gherman, L. Oprean, A. Hangan, R. Oprean, J. BUON, 2015, 20(6), 1623.

21. Yong-Jin Wu, Five-Membered Ring Systems: With $\mathrm{N}$ and $\mathrm{S}$ Atom in Progress in heterocyclic chemistry, Ed. G. W. Gribble, J. A. Joule, ISHC Elsevier, 2015, Vol. 27, chapter 5.5, pp. 287-303.

22. D. Huang, B. Ou, R. L. Prior, J. Agric. Food Chem., 2005, 53, 1841-1856. 